\title{
ANALISIS DAMPAK KEBISINGAN \\ DARI AKTIVITAS PENERBANGAN BANDARA INTERNASIONAL SUPADIO PONTIANAK TERHADAP KONSENTRASI BELAJAR SISWA SEKOLAH
}

Eka Pratama Kurniawan ${ }^{1)}$ Dian Rahayu Jati ${ }^{1)}$ Laili Fitria $^{2)}$

1) Program Studi Teknik Lingkungan Jurusan Teknik Sipil Fakultas Teknik Universitas Tanjungpura, Pontianak

2) Program Studi Teknik Sipil Jurusan Teknik Sipil Fakultas Teknik Universitas Tanjungpura, Pontianak E-mail : eka.nwreat4694@gmail.com

\begin{abstract}
ABSTRAK
SD Negeri 39 Sungai Raya, Kabupaten Kubu Raya merupakan satu diantara fasilitas pendidikan yang berada di sekitar area Bandara Internasional Supadio Pontianak. Jarak bangunan sekolah dengan bandara yang hanya berkisar $450 \mathrm{~m}$, menjadikan kawasan tersebut termasuk kedalam kawasan kebisingan tingkat 3 yang artinya mempunyai gangguan terbesar akibat operasi pesawat udara pada siang dan malam hari. Penelitian ini bertujuan untuk mengetahui tingkat kebisingan di SDN 39 Sungai Raya, Kabupaten Kubu Raya, mengetahui pengaruh kebisingan terhadap konsentrasi belajar siswa yang diuji dengan menyusun puzzle, dan mengetahui upaya yang dapat dilakukan untuk meminimalisir dampak kebisingan bagi para siswa. Metode yang digunakan dalam penelitian ini adalah metode penelitian eksperimen. Penelitian dilakukan dengan tiga tahap, tahap pertama yaitu pengukuran intensitas kebisingan di lokasi penelitian. Tahap kedua, yaitu uji pendahuluan dan tahap ketiga yaitu uji akhir dengan menguji konsentrasi siswa dalam menyelesaikan susunan puzzle dalam waktu 10 menit dengan diberikan paparan kebisingan. Berdasarkan hasil penelitian didapatkan bahwa tingkat kebisingan di SDN 39 Sungai Raya, Kabupaten Kubu Raya telah melebihi baku mutu ambang batas kebisingan untuk kawasan pendidikan dalam hal ini sekolah yang tertuang dalam Keputusan Menteri Negara Lingkungan Hidup Nomor KEP.48/MENLH/11/1996 yaitu sebesar 55 dB. Tingkat kebisingan di SDN 39 Sungai Raya yaitu dengan rentang sebesar 63,8 - 75,5 dBA.Berdasarkan uji regresi menggunakan aplikasi SPSS didapatkan bahwa nilai pengaruh kebisingan terhadap waktu penyelesaian puzzle adalah sebesar $82,5 \%$. Berdasarkan penelitian ini dapat disimpulkan bahwa kebisingan dari aktivitas penerbangan Bandara Internasional Supadio Pontianak mempengaruhi konsentrasi siswa yang diuji menggunakan penyusunan puzzle.
\end{abstract}

Kata Kunci : kebisingan, konsentrasi siswa, puzzle, waktu penyelesaian

\section{ABSTRACT}

SD Negeri 39 Sungai Raya, Regency Kubu Raya is one among the education facilities that are located around the area of the international airport of Supadio Pontianak. The distance of the school buildings with the airport only revolves around $450 \mathrm{~m}$, making the area included into the area of the noise level 3 which means it has the biggest disruption resulting from the operation of aircraft on the afternoon and evening. This research aims to know the level of noise in the SDN 39 Sungai Raya, Regency Kubu Raya, figure out the influence of noise against the concentration of learning students are tested by arranging puzzle, and know the effort it can take to minimize the noise impact for the students. The methods used in this research is experimental research methods. The research is done with three stages, the first stage that is the measurement of the intensity of the noise on site research. The second stage, namely the introduction and test the third stage that is the final test by testing the concentration of students in completing the arrangement of puzzle in 10 minutes with the given exposure to noise. Based on the research results obtained that the noise level in the SDN 39 Sungai Raya, Regency Kubu Raya has exceeded the threshold of quality raw noise to the area of education in this school that are contained in the decision of the Minister of State for the environment Number KEP. 48/MENLH/11/1996, namely of $55 \mathrm{~dB}$. The highest noise level in the SDN 39 Sungai Raya is 86,8 dBA. Based on regression test using SPSS applications obtained that value the influence of noise to the puzzle settlement time is 82.5\%. Based on this study it can be concluded that the noise from the Supadio International Airport Pontianak aviation activity affect student concentrations that tested using the preparation puzzle.

Keywords: noise, concentration of students, puzzle, time of completion 


\section{PENDAHULUAN}

Umumnya kebisingan di daerah perkotaan dihasilkan melalui sumber yang berbeda, seperti aktivitas lalu lintas, kegiatan komersial, industri, daerah pemukiman, aktivitas bandara, dan sebagainya. SD Negeri 39 Sungai Raya, Kabupaten Kubu Raya merupakan satu diantara fasilitas pendidikan yang berada di sekitar area Bandara Internasional Supadio Pontianak. Jarak bangunan sekolah dengan bandara yang hanya berkisar $450 \mathrm{~m}$. Menurut Perda Prov. Kalimantan Barat No. 2 Tahun 2008 tentang Pengendalian Kawasan Keselamatan dan Operasi Penerbangan (KKOP) dan Kawasan Kebisingan Bandar Udara (KKB), Pasal 18 ayat 1, bangunan SDN 39 Sungai Raya termasuk kedalam kawasan kebisingan tingkat 3 yang artinya mempunyai gangguan terbesar akibat operasi pesawat udara pada siang dan malam hari. Oleh karena itu, akan dilakukan penelitian mengenai dampak kebisingan dari aktivitas penerbangan Bandara Internasional Supadio Pontianak terhadap konsentrasi siswa SDN 39 Sungai Raya, Kabupaten Kubu Raya. Tujuan penelitian ini yaitu untuk mengetahui tingkat kebisingan di SDN 39 Sungai Raya, Kabupaten Kubu Raya, mengetahui pengaruh kebisingan terhadap konsentrasi belajar siswa yang diuji dengan menyusun puzzle, dan mengetahui upaya yang dapat dilakukan untuk meminimalisir dampak kebisingan bagi para siswa. Oleh karena itu, penelitian ini diharapkan dapat memberikan manfaat bagi warga SDN 39 Sungai Raya, Kabupaten Kubu Raya seperti pihak sekolah dan masyarakat sekitar.

\section{METODOLOGI PENELITIAN}

1. VARIABEL PENELITIAN

- $\quad$ Variabel Independen (Variabel Bebas)

Variabel independen dalam penelitian ini yaitu intensitas kebisingan dari aktivitas penerbangan bandara.

- Variabel Dependen (Variabel Terikat)

Variabel dependen dalam penelitian ini yaitu konsentrasi siswa dan waktu yang diperlukan siswa dalam menyelesaikan susunan puzzle dengan benar.

- Variabel Kontrol

Variabel kontrol dalam penelitian ini yaitu kemampuan siswa dalam menyelesaikan susunan puzzle tanpa adanya paparan kebisingan.

\section{METODE PENELITIAN}

Metode yang digunakan dalam penelitian ini adalah metode penelitian eksperimen yang bertujuan untuk menganalisis dampak tingkat kebisingan yang akan dimanupulasi dengan rekaman suara kebisingan terhadap konsentrasi siswa dalam menyelesaikan susunan puzzle. Penelitian akan dibagi menjadi tiga tahap yakni:

- Melakukan pengukuran intensitas kebisingan di lokasi penelitian yang akan dijadikan rujukan sebagai suara bising yang akan dipaparkan kepada siswa.

- Uji pendahuluan. Siswa diberikan waktu selama 10 menit untuk dapat menyelesaikan puzzle tanpa diberikan paparan kebisingan.

- Uji akhir. Siswa juga diberikan waktu selama 10 menit untuk dapat menyelesaikan puzzle dengan diberikan paparan kebisingan sesuai dengan intensitas dari aktivitas penerbangan bandara selama penyelesaian puzzle. 


\section{LOKASI PENELITIAN}

Penelitian ini dilakukan di SD Negeri 39 Sungai Raya yang terletak di Jalan Merdeka II, Kabupaten Kubu Raya. Jarak lokasi SDN 39 Sungai Raya dengan Bandara Internasional Supadio Pontianak yakni $\pm 450 \mathrm{~m}$.

\section{WAKTU PENELITIAN}

Penelitian ini dilaksanakan pada hari aktif sekolah selama 4 hari yakni pada hari Rabu, 17 Agustus 2016; Kamis, 18 Agustus 2016; Rabu, 24 Agustus 2016 dan Kamis, 25 Agustus 2016. Hari pertama dan kedua penelitian dimaksudkan untuk mengukur tingkat kebisingan di lokasi penelitian. Pengukuran tingkat kebisingan dilakukan pada waktu masuk hingga pulang sekolah yakni pukul 07.00-12.00 WIB. Pengukuran dibagi menjadi 3 sesi yaitu pada pukul 07.00-09.00 WIB, 09.15 - 11.00 WIB dan 11.15-12.00 WIB. Hari ketiga pelaksanaan dimaksudkan untuk uji pendahuluan sedangkan hari keempat dimaksudkan untuk uji akhir.

5.

METODE PEMILIHAN SAMPEL (RESPONDEN)

Sampel yang diambil dalam penelitian ini yaitu total populasi dari siswa kelas $\mathrm{V}$ dan VI di SDN 39 Sungai Raya yakni sejumlah 66 siswa. Penentuan jumlah sampel didasarkan pada teori Roscoe (1975) yang dikutip oleh Uma Sekaran (2006) dengan tujuan untuk memperkecil peluang kesalahan generalisasi.

6.

\section{SUMBER DATA PENELITIAN}

Pengumpulan data bertujuan untuk mendapatkan data-data yang diperlukan untuk keperluan penelitian. Data-data yang dibutuhkan, yaitu:

1. Data Primer

Data primer yang digunakan dalam penelitian ini, yaitu:

a. Tingkat intensitas kebisingan di lingkungan Sekolah Dasar Negeri 39 Sungai Raya

b. Rujukan waktu penyusunan puzzle

c. Banyaknya siswa yang mampu menyelesaikan puzzle dalam waktu 10 menit (rujukan waktu) dengan dan tanpa paparan kebisingan.

2. Data Sekunder

Data sekunder yang digunakan sebagai data pendukung dan pelengkap dari data primer yang ada relevansinya dengan penelitian ini, yaitu:

a. Jadwal penerbangan yang didapat dari Bandara Internasional Supadio Pontianak

b. Jumlah siswa kelas V dan VI pada SDN 39 Sungai Raya

c. Denah lokasi kelas pada SDN 39 Sungai Raya

d. Jarak Bandara Internasional Supadio Pontianak dan SDN 39 Sungai Raya.

7.

INSTRUMEN PENELITIAN

Pengumpulan data dilakukan dengan menggunakan alat-alat, yaitu pulpen, kertas, laptop, Sound Level Meter, Puzzle, Stopwatch, Tape Recorder, dan Speaker.

8.

METODE ANALISA DATA

Analisa data yang digunakan yakni analisa data bivariat untuk mengetahui kemaknaan hubungan/pengaruh variabel bebas (intensitas kebisingan) terhadap variabel terikat (konsentrasi siswa dan waktu penyelesaian puzzle). Sebelum menentukan metode uji yang akan digunakan maka harus diketahui terlebih dahulu apakah data yang didapat dari hasil penelitian terdistribusi normal atau tidak normal. Metode yang digunakan yakni dengan uji normalitas Kolmogorov-Smirnov dengan SPSS. 
Setelah hasil uji normalitas didapatkan, maka dapat ditentukan metode uji yang akan digunakan apakah dengan uji regresi, korelasi atau metode lainnya.

\section{HASIL DAN PEMBAHASAN}

A. ANALISIS KEBISINGAN PADA SEKOLAH

\section{- GAMBARAN UMUM LOKASI SEKOLAH}

SDN 39 Sungai Raya memiliki 8 ruang kelas dengan 7 ruang kelas yang aktif digunakan dan satu ruang kelas dalam keadaan kosong atau tidak digunakan. Bentuk bangunan sekolah berbentuk huruf $U$ dan posisi ruang kelas tersebut tepat menghadap landasan pacu Bandara Internasional Supadio Pontianak. Selain itu, di sekitar lokasi sekolah juga minim vegetasi yang dapat mengurangi tingkat kebisingan dari aktivitas penerbangan bandara. Barrier atau penghalang antara lokasi bandara dan sekolah hanya dibatasi oleh tembok beton yang memiliki ketinggian \pm 2 meter serta beberapa pohon yang ada di sekitar pemukiman warga. Lokasi sekolah berada tepat di sekitar pemukiman warga. Berdasarkan hasil pengamatan, tidak ada sumber kebisingan lain yang signifikan seperti kendaraan bermotor ataupun aktivitas masyarakat lainnya yang mempengaruhi kebisingan di lokasi penelitian.

\section{- $\quad$ ANALISIS JARAK BANGUNAN SEKOLAH}

Berdasarkan Perda Prov. Kalimantan Barat No. 2 Tahun 2008 tentang Pengendalian Kawasan Keselamatan dan Operasi Penerbangan (KKOP) dan Kawasan Kebisingan Bandar Udara (KKB), Pasal 18 ayat 1 lokasi bangunan SDN 39 Sungai Raya termasuk kedalam kawasan kebisingan tingkat 3 yang artinya mempunyai gangguan terbesar akibat operasi pesawat udara pada siang dan malam hari. Hal tersebut dikarenakan jarak dari SDN 39 Sungai Raya ini terhadap landasan pacu Bandara Internasional Pontianak sekitar \pm 450 meter.

\section{- $\quad$ ANALISIS TINGKAT KEBISINGAN DI RUANG KELAS SEKOLAH}

Kebisingan yang terjadi di SDN 39 Sungai Raya, Kabupaten Kubu Raya termasuk dalam jenis kebisingan intermitten atau kebisingan yang terputus-putus. Kebisingan intermitten atau kebisingan terputus-putus diartikan bahwa kebisingan yang dihasilkan oleh sumber bising berlangsung secara tidak terus-menerus melainkan ada periode relatif tenang dan ada periode bising. Tingkat kebisingan di SDN 39 Sungai Raya diukur menggunakan sound level meter (SLM) yang dapat dilihat pada Tabel 2 dan Tabel 3.

Tabel 2. Tingkat Kebisingan pada Masing-masing Ruang Kelas SDN 39 Sungai Raya, Kabupaten Kubu Raya pada Saat Tidak Ada Pesawat

\begin{tabular}{|c|c|c|c|c|c|}
\hline \multirow{3}{*}{ Kelas } & \multicolumn{2}{|c|}{ Koordinat } & \multirow{2}{*}{\multicolumn{3}{|c|}{$\begin{array}{c}\text { Tingkat Kebisingan (dB) } \\
\text { Waktu Pengukuran }\end{array}$}} \\
\hline & \multirow{2}{*}{$\begin{array}{l}\text { Lintang Selatan } \\
\text { (LS) }\end{array}$} & \multirow{2}{*}{$\begin{array}{l}\text { Bujur Timur } \\
\text { (BT) }\end{array}$} & & & \\
\hline & & & $07.00-09.00$ & $09.15-11.00$ & $11.15-12.00$ \\
\hline 1 & $0^{\circ} 8^{\prime} 51.60^{\prime \prime}$ & $109^{\circ} 23^{\prime} 51.46^{\prime \prime}$ & 62,3 & 60,5 & 62,4 \\
\hline 2 & $0^{\circ} 8^{\prime} 50.82^{\prime \prime}$ & $109^{\circ} 23^{\prime} 50.89^{\prime \prime}$ & 61.5 & 61.9 & 61.6 \\
\hline 3 & $0^{\circ} 8^{\prime} 50.43^{\prime \prime}$ & $100^{\circ} 23^{\prime} 50.66^{\prime \prime}$ & 50,1 & 60 & 61,1 \\
\hline 4 & $0^{\circ} 8^{\prime} 50.15^{\prime \prime}$ & $109^{\circ} 23^{\prime} 50.50^{\prime \prime}$ & 60,7 & 62 & 61,4 \\
\hline 5 & $0^{\circ} 8^{\prime} 49.93 "$ & $109^{\circ} 23^{\prime} 50.36^{\prime \prime}$ & 62,1 & 62,7 & 60.3 \\
\hline 6 & $0^{\circ} 8^{\prime} 49.71^{\prime \prime}$ & $109^{\circ} 23^{\prime} 50.25^{\prime \prime}$ & 60,7 & 61,5 & 59 \\
\hline
\end{tabular}


Tabel 3. Tingkat Kebisingan pada Masing-masing Ruang Kelas SDN 39 Sungai Raya, Kabupaten Kubu Raya pada Saat Ada Pesawat

\begin{tabular}{|c|c|c|c|c|c|}
\hline \multirow{3}{*}{ Kelas } & \multicolumn{2}{|c|}{ Kourdinat } & \multirow{2}{*}{\multicolumn{3}{|c|}{$\begin{array}{c}\text { Tiugkat Kebisingau (dB) } \\
\text { Waktu Pengukuran }\end{array}$}} \\
\hline & \multirow{2}{*}{$\begin{array}{l}\text { Lintang Selatan } \\
\text { (LS) }\end{array}$} & \multirow{2}{*}{$\begin{array}{c}\text { Bujur Timur } \\
\text { (BT) }\end{array}$} & & & \\
\hline & & & $07.00-09.00$ & $09.15-11.00$ & $11.15-12.00$ \\
\hline 1 & $0^{\circ} 3^{\prime} 50.50^{\prime \prime}$ & $109^{\circ} 23^{\prime} 51.46^{\prime \prime}$ & 78.9 & 81.9 & 82.3 \\
\hline 2 & $0^{\circ} 3^{\prime} 50.82^{\prime \prime}$ & $109^{\circ} 23^{\prime} 50.89^{\prime \prime}$ & 78,3 & 83,3 & 79,2 \\
\hline 3 & $0^{\circ} 3^{\prime} 50.43^{\prime \prime}$ & $109^{\circ} 23^{\prime} 50.66^{\prime \prime}$ & 81.7 & 77.4 & 86.8 \\
\hline 4 & $0^{\circ} 3^{\prime} 50.15^{\prime \prime}$ & $109^{\circ} 23^{\prime} 50.50^{\prime \prime}$ & 79,5 & 83,8 & 77,6 \\
\hline 5 & $0^{\circ} 3^{\prime} 49.93^{\prime \prime}$ & $109^{\circ} 23^{\prime} 50.36^{\prime \prime}$ & 78,6 & 75.2 & 76.7 \\
\hline 6 & $0^{\circ} 3^{\prime} 49.71^{\prime \prime}$ & $109^{\circ} 23^{\prime} 50.25^{\prime \prime}$ & 83,5 & 83,4 & 79,2 \\
\hline
\end{tabular}

Berdasarkan Tabel $\mathbf{2}$ dan Tabel $\mathbf{3}$ diatas dapat dilihat bahwa tingkat kebisingan yang terukur di masing-masing ruang kelas SDN 39 Sungai Raya melebihi ambang batas kebisingan untuk kawasan pendidikan dalam hal ini sekolah yang tertuang dalam Keputusan Menteri Negara Lingkungan Hidup Nomor KEP.48/MENLH/11/1996, yaitu sebesar $55 \mathrm{~dB}$. Tingkat kebisingan tertinggi terdapat di ruang kelas 3 yaitu sebesar 86,8 dB pada rentang waktu pengukuran pukul $11.15-12.00$ WIB. Hal ini disebabkan ruang kelas 3 berhadapan langsung dengan landasan pacu Bandara Internasional Supadio Pontianak. Selain itu, di depan kelas juga minim barrier atau penghalang kebisingan baik dari bangunan lain maupun dari vegetasi tanaman di depan ruang kelas yang berhadapan langsung dengan halaman sekolah. Sedangkan tingkat kebisingan terendah terdapat di ruang kelas 5 yaitu sebesar $75,2 \mathrm{~dB}$ pada rentang waktu pengukuran pukul $09.15-11.00$ WIB. Hal ini disebabkan lokasi ruang kelas tersebut yang terhalang oleh barrier atau penghalang berupa vegetasi tanaman pohon pucuk merah dan terhalang oleh bangunan perpustakaan dan ruang guru sehingga suara bising dari mesin pesawat sedikit terhalang.

\section{B. $\quad$ ANALISIS UJI PENDAHULUAN DAN UJI AKHIR}

Metode yang digunakan dalam penelitian ini adalah penelitian eksperimen. Tujuan dari penelitian eksperimen ini yaitu untuk menemukan hubungan sebab-akibat dan pengaruh faktor-faktor dalam kondisi tertentu. Penelitian ini akan menganalisis dampak kebisingan terhadap konsentrasi siswa dalam belajar yang diuji dengan cara menyusun potongan puzzle (Gambar 4 dan Gambar 5).

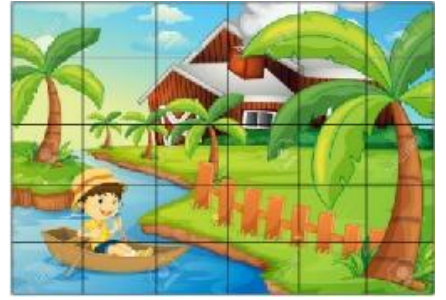

Gambar 4. Puzzle untuk Uji Pendahuluan

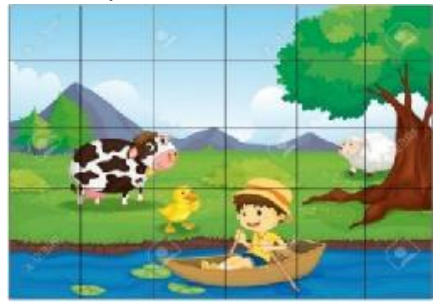

Gambar 5. Puzzle untuk Uji Akhir

Penggunaan puzzle yang relatif sama bertujuan agar siswa yang berhasil dalam uji pendahuluan tidak menghafal gambar puzzle yang sudah pernah mereka selesaikan. Sehingga hasil yang diujikan kepada siswa tersebut dapat benar-benar menjelaskan perbedaan hasil antara uji pendahuluan yang dilakukan dalam kondisi normal (tanpa adanya gangguan kebisingan) dan kondisi yang diberikan paparan kebisingan.

Tahap pertama siswa akan diberikan uji pendahuluan berupa tes uji menyusun puzzle dalam keadaan normal atau tanpa gangguan paparan kebisingan. Sedangkan tahap kedua dilakukan terhadap siswa yang berhasil menyelesaikan susunan puzzle dengan benar dalam waktu $\leq 10$ menit. Uji tahap kedua dikondisikan sedemikian rupa dengan memberikan gangguan berupa paparan kebisingan dari hasil rekaman mesin pesawat yang berada di sekitar sekolah dengan bantuan sound system atau speaker. Berdasarkan hasil uji pendahuluan didapatkan siswa yang berhasil menyelesaikan 
susunan puzzle dengan benar dalam waktu kurang dari sama dengan 10 menit dapat dilihat pada dan Tabel $\mathbf{4}$ dan Tabel 5.

\begin{tabular}{|c|c|c|c|c|c|c|c|c|c|c|c|c|c|}
\hline \multirow[b]{2}{*}{$\mathrm{Na}$} & \multirow[b]{2}{*}{ ID Fesponden } & \multicolumn{4}{|c|}{ 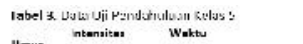 } & \multirow[b]{2}{*}{$\begin{array}{l}\text { Lulus/Tidak } \\
\text { Lulue }\end{array}$} & \multicolumn{7}{|c|}{ Tabel 4. Vata Uii l'endahuluan Kelas b } \\
\hline & & $\begin{array}{c}\text { Umur } \\
\text { (tohhur) }\end{array}$ & $\begin{array}{l}\text { Kebsentes } \\
\text { (AB) }\end{array}$ & $\begin{array}{l}\text { Penyeletsisn } \\
\text { (mentit) }\end{array}$ & Rannkkne & & No. & ID Raspanden & $\begin{array}{l}\text { Umur } \\
\text { (tatahun) }\end{array}$ & $\begin{array}{l}\text { Intensitos } \\
\text { Kabisisingan }\end{array}$ & $\begin{array}{c}\text { Wakktu } \\
\text { Panywlessien }\end{array}$ & Rangking & $\begin{array}{l}\text { Lulus/Tidsk } \\
\text { Lulus }\end{array}$ \\
\hline 1 & Puntin & 11 & אิA & 98.36 & 1 & Fal.us & & & & & & & \\
\hline 2 & (נצ' & 11 & oss & ws.se & 2 & :دادا: & 1 & Mndtlik.a & 12 & 63.8 & 5.50 & 1 & Luiles \\
\hline$=$ & kumla & 11 & was & $u s$ & 3 & Las & , & Noลลang & 12 & $\omega, \alpha, s$ & 6.44 & 7 & iwhas \\
\hline 1 & Ircish & 11 & iss & as & : & :دادا & 3 & risal & 12 & 63.8 & 7.20 & 3 & Luivs \\
\hline 5 & Siltw & 11 & 193 & 05.51 & 5 & at.s. & A & Parrits & 12 & 63.8 & 8.03 & 1 & Luiles \\
\hline - & $\cos x$ & $"$ & $\sin$ & inas & n & tul. & $\therefore$ & radill & 12 & asi,s & x.4. & $\therefore$ & I whas \\
\hline í & Fiveri & 11 & is 8 & 1/3 & . & Lats & : & Systhri & 12 & 63.8 & 8.52 & : & weles \\
\hline 3 & Wingati & 11 & 683 & (3)1 & 8 & tilus & 7 & Fvilikit & 12 & 63,8 & 0.37 & 7 & I whes \\
\hline 3 & Itr. & $\begin{array}{l}11 \\
11\end{array}$ & ias & 0.5 & a & talis. & 8 & Wondl & 12 & 6.8 & 3.21 & 8 & Lulks \\
\hline 10 & Neron & 11 & ระ.ก & $\cos 25$ & 11 & :دادا: & 9 & KI|k1 & 12 & $x<, x$ & 1.,5s & 9 & inata \\
\hline 11 & Watyu lecclan & 11 & wa & رذ & 11 & & & & & & & & 16at \\
\hline
\end{tabular}

Berdasarkan Tabel 4 dan Tabel 5 dapat dilihat bahwa dari 34 siswa kelas 5 dan 32 siswa kelas VI yang mengikuti uji pendahuluan terdapat 11 siswa kelas $V$ dan 9 siswa kelas $\mathrm{VI}$ yang berhasil menyelesaikan susunan puzzle dengan benar dalam waktu $\leq 10$ menit. Waktu tersebut yang menjadi waktu rujukan untuk uji pendahuluan karena telah dilakukan uji terlebih dahulu sebelum dilakukannya penelitian ini kepada siswa kelas 5 dan kelas 6. Rata-rata anak kelas 5 dan kelas 6 dapat menyelesaikan susunan puzzle dalam waktu kurang lebih 10 menit. Sedangkan dari 32 siswa kelas 6 yang mengikuti uji pendahuluan, hanya 9 siswa yang berhasil menyelesaikan susunan puzzle dengan benar dalam waktu kurang dari sama dengan 10 menit. Berdasarkan pengujian ini dapat dilihat bahwa umur atau tingkat kelas belum tentu menentukan apakah seorang siswa dapat lebih berkonsentrasi dalam memecahkan masalah dalam hal ini dengan menyusun puzzle yang dikaitkan dengan konsentrasi siswa dalam belajar.

Uji akhir dilakukan pada hari yang berbeda tepatnya sehari setelah uji pendahuluan. Hal ini bertujuan agar siswa dapat dikondisikan dalam suatu ruangan yang sama dengan perlakuan yang sama. Berdasarkan hasil uji akhir didapatkan siswa yang berhasil menyelesaikan susunan puzzle dengan benar sampai selesai dapat dilihat pada Tabel 6.

\begin{tabular}{|c|c|c|c|c|c|c|}
\hline No. & IV Kcsponden & $\underset{\text { (tahur }}{\text { Umur) }}$ & $\begin{array}{l}\text { Intcrnstas } \\
\text { Kcbisingan } \\
\text { (dE) }\end{array}$ & $\begin{array}{l}\text { Woiktu } \\
\text { I'cnyelssion } \\
\text { (menit) }\end{array}$ & Kōngking & $\begin{array}{l}\text { Lulus// i dak } \\
\text { Lulus }\end{array}$ \\
\hline 1 & zuled & 11 & 75,5 & 14.55 & 13 & Ti.jak Lulus \\
\hline 7 & Diul- & 11 & 79,5 & [4 5 ח & $s$ & lulus \\
\hline 7 & surnin & 11 & $7 \mathrm{~T}, \mathrm{~F}$ & $r a<a$ & 9 & lutures \\
\hline 4 & indzh & 11 & 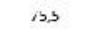 & ב.S. & 11 & II dak Lulus \\
\hline 5 & Eltra & 11 & 75,5 & c9.50 & 10 & Lulus \\
\hline $\mathrm{s}$ & zoya & 11 & 75,5 & 18.35 & 20 & TIak Lulus \\
\hline ; & Futi & 11 & 75,5 & 17.10 & 18 & Ti.jek Lulus \\
\hline 5 & W'ahyud & 11 & 79,5 & 0.41 & , & Iuluse \\
\hline 2 & bnu & 11 & 1,3 & 0,3 & , & Lulus \\
\hline 10 & Nova & 11 & ל, & 15.23 & 11 & IItak Lulus \\
\hline 11 & Wahyu Ferdan & 11 & 75,5 & 16.00 & 15 & Trdak Lulus \\
\hline 12 & Sirsthike & 12 & 75,5 & c8.s9 & 8 & Lulus \\
\hline 11 & Nansne & 12 & $7 \mathrm{r}, \mathrm{s}$ & $03<2$ & 1 & I whers \\
\hline 14 & Tizal & 12 & 75,5 & 14.52 & 12 & Tirdak Lulus \\
\hline 13 & $\operatorname{arcz}$ & 12 & $1, b$ & Lb.21 & b & Lulus \\
\hline 1 a & Fadill & 12 & 75.5 & 07.02 & 6 & Lulus \\
\hline 17 & Systhi & 12 & 75,5 & C4.59 & 4 & Lulus, \\
\hline 1 a & re-ikn & 12 & $7 \mathrm{r}, \mathrm{r}$ & $16 r_{5 i}$ & 16 & Titak I Iulus \\
\hline 19 & Wendi & 12 & 75,5 & 17.00 & 17 & Titak Lulus \\
\hline 24 & kikı & 12 & ל, & 18.24 & 15 & IIdak Lulus \\
\hline
\end{tabular}

Berdasarkan Tabel 6 dapat dilihat bahwa siswa mampu menyelesaikan susunan puzzle dengan benar dalam waktu yang variatif. Selain itu, diketahui bahwa dari 20 siswa yang ikut dalam uji akhir ini, 50\% siswa mampu menyelesaikan susunan puzzle dalam waktu kurang dari sama dengan 10 menit dan 50\% siswa lainnya tidak mampu menyelesaikan susunan puzzle dalam waktu kurang dari sama dengan 10 menit. Hal ini membuktikan bahwa tingkat kebisingan mempengaruhi konsentrasi siswa dalam menyelesaikan susunan puzzle dengan benar. 


\section{ANALISIS UJI NORMALITAS DAN UJI REGRESI SEDERHANA}

Analisis uji normalitas merupakan analisis yang dilakukan untuk mengetahui apakah data kebisingan dan waktu penyelesaian puzzle pada uji pendahuluan terdistribusi normal atau tidak. Hal ini dilakukan untuk mengetahui metode yang tepat untuk melakukan uji korelasi pada tahap selanjutnya. Analisis uji normalitas ini dilakukan menggunakan aplikasi SPSS (Statistic Product and Service Solutions) yakni dengan uji normalitas Kolmogorov-Smirnov. Analisis uji normalitas Kolmogorov-Smirnov memiliki kriteria, jika nilai siginifikansi $>0,05$ maka data terdistribusi normal sedangkan jika nilai siginifikansi $<0,05$ maka data tidak terdistribusi normal. Hasil analisis uji normalitas Kolmogorov-Smirnov menggunakan aplikasi SPSS dapat dilihat pada Tabel 7.

Tabel 7. Hasil Uji Normalitas Kolmogorov-Smirnov menggunakan aplikasi SPSS

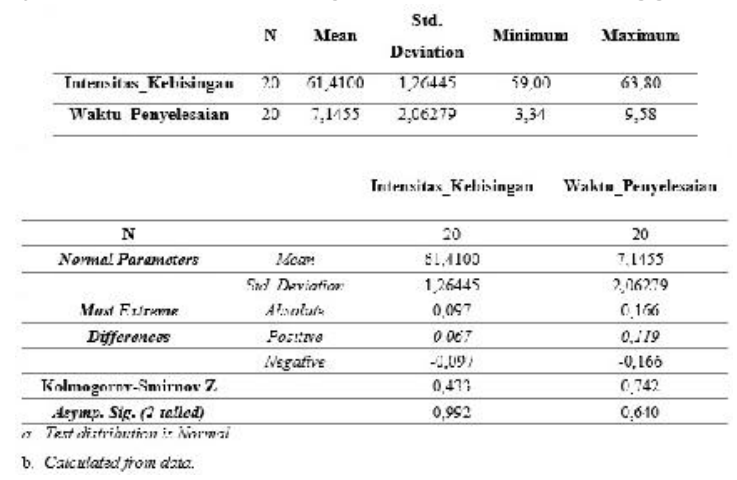

Berdasarkan hasil analisis, dapat dilihat bahwa nilai signifikansi untuk intensitas kebisingan yaitu sebesar 0,992 dan nilai signifikansi untuk waktu penyelesaian yaitu sebesar 0,640. Hal ini berarti nilai signifikansi dari kedua data tersebut $>0,05$, ini menunjukkan bahwa data yang di dapat dari penelitian ini terdistribusi normal. Setelah diketahui bahwa data terdistribusi normal, selanjutnya menentukan metode yang tepat untuk menguji hubungan diantara variabel terikat (tingkat kebisingan) dan variabel bebas (waktu penyelesaian puzzle). Hal ini dilakukan untuk mengetahui apakah tingkat kebisingan berpengaruh terhadap konsentrasi siswa dalam menyelesaikan susunan puzzle. Analisis yang dapat digunakan dalam penelitian ini yaitu dengan metode uji regresi sederhana. Hasil analisis uji regresi sederhana menggunakan aplikasi SPSS dapat dilihat pada Tabel 8 sampai Tabel 11.

Tabel 8. Output Bagian Pertama (Variable Entered/Removed)

\begin{tabular}{|c|c|c|c|}
\hline Model & Vaviables Ertered & $\begin{array}{l}\text { Vurrables } \\
\text { Removiad }\end{array}$ & Method \\
\hline 1 & Sclisih Kcbisingan & & Entsr \\
\hline
\end{tabular}

Setelah itu, dilakukan analisis perhitungan besarnya nilai korelasi/hubungan (R) yaitu sebesar 0,909 dan dijelaskan besarnya prosentase pengaruh variabel bebas terhadap variabel terikat yang disebut koefisien determinasi yang merupakan hasil dari pengkuadratan $R$ (Tabel 9). Berdasarkan output tersebut diperoleh koefisien determinasi (R2) sebesar 0,825 yang mengandung pengertian bahwa pengaruh variabel bebas (kebisingan) terhadap variabel terikat (waktu penyelesaian puzzle) adalah sebesar $82,5 \%$, sedangkan sisanya dipengaruhi oleh variabel yang lain.

Tabel 9. Output Bagian Kedua (Model Summary)

\begin{tabular}{lcccc} 
Model & $\mathbf{R}$ & $\begin{array}{c}\mathbf{R} \\
\text { Square }\end{array}$ & $\begin{array}{c}\text { Adjusted } \\
\mathbf{R} \text { Square }\end{array}$ & $\begin{array}{c}\text { Std. Error of } \\
\text { the Estimate }\end{array}$ \\
\hline $\mathbf{1}$ & $0,909^{\mathrm{a}}$ & 0,825 & 0,816 & 2,25765 \\
\hline a. & Predictors: (Constant, Selisih_Kebisingan &
\end{tabular}


Tabel 10 ini untuk menjelaskan hubungan antara pengaruh yang nyata (signifikan) variabel kebisingan $(\mathrm{X})$ terhadap variabel waktu penyelesaian $(\mathrm{Y})$. Berdasarkan output tersebut terlihat bahwa $\mathrm{F}$ hitung $=85,128$ dengan tingkat signifikansi/probabilitas 0,000 $<0,05$, maka model regresi dapat dipakai untuk memprediksi variabel waktu penyelesaian.

Tabel 10. Output Bagian Ketiga (ANOVA)

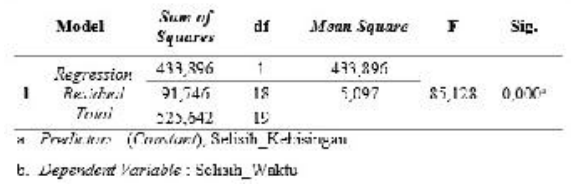

Berdasarkan Tabel 11, pada kolom B pada nilai Constant (a) adalah $-6,840$ dan nilai kebisingan (b) adalah 0,938 , sehingga regresinya dapat ditulis:

$$
\mathrm{Y}=\mathrm{a}+\mathrm{bX} \text { atau }-6,840+0,938 \mathrm{X}
$$

Tabel 11. Output Bagian Keempat (Coefficients)

\begin{tabular}{|c|c|c|c|c|c|c|}
\hline \multirow{2}{*}{\multicolumn{2}{|c|}{ Model }} & \multicolumn{2}{|c|}{$\begin{array}{l}\text { Unstandardized } \\
\text { Corfficients }\end{array}$} & \multirow{2}{*}{$\begin{array}{c}\begin{array}{c}\text { Standardized } \\
\text { Coofficients }\end{array} \\
\text { Beta }\end{array}$} & \multirow[t]{2}{*}{ t } & \multirow[t]{2}{*}{ Siz. } \\
\hline & & B & Std Irror & & & \\
\hline \multirow{2}{*}{1} & (Constant) & $-6,340$ & 1,286 & \multirow{2}{*}{0.909} & $.5,319$ & 0,000 \\
\hline & Selisit_Kebisingan & 0.978 & $0,107$. & & $9.72 \pi 0^{\circ}$ & 3000 \\
\hline
\end{tabular}

Koefisien b dinamakan koefisien arah regresi dan menyatakan perubahan ratarata variabel $Y$ untuk setiap perubahan variabel $X$ sebesar satu satuan. Perubahan ini merupakan pertambahan bila $\mathrm{b}$ bertanda positif dan penurunan bila $\mathrm{b}$ bertanda negatif. Sehingga dari persamaan tersebut dapat diterjemahkan:

- Konstanta sebesar -6,840 menyatakan bahwa jika tidak ada nilai kebisingan maka nilai waktu penyelesaian sebesar $-6,840$.

- Koefisien regresi $X$ sebesar 0,938 menyatakan bahwa setiap penambahan 1 nilai kebisingan, maka nilai waktu penyelesaian bertambah sebesar 0,938. Koefisien regresi variabel kebisingan $(X)$ adalah 0,938 bernilai positif $(+)$, sehingga dapat dikatakan bahwa kebisingan $(X)$ berpengaruh positif terhadap waktu penyelesaian $(\mathrm{Y})$. Pengaruh positif diartikan bahwa semakin meningkat kebisingan $(X)$ maka akan meningkat pula waktu penyelesaian $(\mathrm{Y})$.

Selain menggambarkan persamaan regresi, output ini juga menampilkan uji signifikansi dengan uji t yaitu untuk mengetahui apakah ada pengaruh yang nyata (signifikan) variabel kebisingan $(X)$ sendiri (partial) terhadap variabel waktu penyelesaian (Y).

Hipotesis:

- Ho : Tidak ada pengaruh yang nyata (signifikan) variabel kebisingan (X) terhadap variabel waktu penyelesaian $(\mathrm{Y})$

- H1 : Ada pengaruh yang nyata (signifikan) variabel kebisingan $(X)$ terhadap variabel waktu penyelesaian ( $\mathrm{Y}$ ).

Berdasarkan output bagian keempat pada Gambar 10 dapat diketahui nilai t hitung lebih besar dibandingkan nilai t tabel yaitu 9,226 $>2,101$. Nilai $t$ tabel dihitung menggunakan rumus:

$\mathrm{t}$ tabel $=$ (tingkat kepercayaan : 2 ; jumlah responden - jumlah variabel bebas -1$)$

$\mathrm{t}$ tabel $=(\alpha: 2 ; \mathrm{n}-\mathrm{k}-1)$

$\mathrm{t}$ tabel $=(0,05: 2 ; 20-1-1)$

$\mathrm{t}$ tabel $=(0,025 ; 18)$

Nilai $t$ tabel tersebut kemudian dicari pada distribusi nilai t tabel (Lampiran) maka ditemukan nilai $t$ tabel sebesar 2,101. Sedangkan nilai signifikansi pada Gambar 10 
diketahui sebesar 0,000 <0,05, maka Ho ditolak dan H1 diterima, yang berarti ada pengaruh yang nyata (signifikan) variabel kebisingan $(X)$ terhadap variabel waktu penyelesaian (Y).

D. ANALISIS DAMPAK KEBISINGAN TERHADAP KONSENTRASI SISWA

Tabel 12. Data Uji Akhir Kelas 5 dan Kelas 6

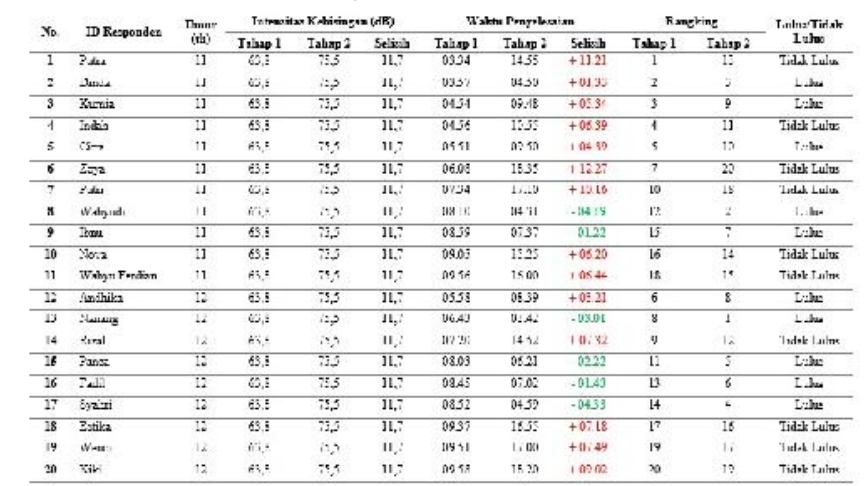

Keterangan :

Lulus $\quad$ : Waktu penyelesaian puzzle kurang dari sama dengan 10 menit

Tidak Lulus : Waktu penyelesaian puzzle lebih dari 10 menit

: Melebihi waktu penyelesaian tahap 1

: Kurang dari waktu penyelesaian tahap 1

Berdasarkan Tabel 12 dapat dilihat bahwa siswa yang berhasil menyelesaikan susunan puzzle dalam waktu kurang dari sama dengan 10 menit sebanyak 10 siswa atau $50 \%$ dari responden yang lulus pada uji pendahuluan. Sedangkan 10 siswa lainnya mampu menyelesaikan susunan puzzle lebih dari waktu yang ditentukan yaitu 10 menit.

\section{E. UPAYA MENGATASI KEBISINGAN DI SDN 39 SUNGAI RAYA}

Upaya untuk mengurangi tingkat kebisingan akibat aktivitas penerbangan Bandara Internasional Supadio Pontianak dapat dilakukan dengan cara sebagai berikut:

1. Penanggulangan kebisingan di areal tepi luar bandara dapat dilakukan dengan pemasangan peredam bising (BPB) berupa penghalang alami (natural barrier). Penghalang alami dapat menggunakan kombinasi tanaman dengan gundukan (berm) tanah. Tanaman yang dapat digunakan berupa bambu pringgodani (Bambuga $S p$ ) karena tanaman ini mampu meredam kebisingan sebesar 14,7 dB dengan volume kerimbunan daun sebesar 366,08 $\mathrm{m} 3$ dan tinggi $1,2 \mathrm{~m}$ (PU, 2005).

2. Penanggulangan kebisingan di sekitar bangunan sekolah yaitu dengan membuat barrier atau penghalang kebisingan dalam bentuk pagar sekolah yang lebih tinggi dan rapat seperti bangunan beton sehingga kebisingan dapat direduksi ataupun dipantulkan. Tepian dalam pagar juga dapat ditambah tanaman bambu-bambuan (Bambusa vulgaris) untuk dapat mereduksi kebisingan. Penanggulangan dengan menggunakan jalur hijau yaitu dengan menanam pohon di sekitar lokasi sekolah. Pohon dapat meredam suara dengan cara mengabsorpsi gelombang suara oleh daun, cabang, dan ranting. Jenis tumbuhan yang paling efektif untuk meredam suara salah satunya adalah kembang sepatu (Hibiscus rosa sinensis L.) mampu mereduksi kebisingan sebesar 31,3 dBA (Setyorini, 2015).

3. Perlu adanya pertimbangan untuk pemindahan lokasi sekolah ke tempat yang lebih kondusif yang jauh dari bandara atau minimal berada di bawah kawasan permukaan kerucut. Hal ini dikarenakan lokasi sekolah berada dalam kawasan permukaan horizontal dalam atau kawasan kebisingan tingkat 3 berdasarkan Perda Provinsi Kalimantan Barat No. 2 Tahun 2008 tentang Pengendalian Kawasan Keselamatan dan 
Operasi Penerbangan (KKOP) dan Kawasan Kebisingan Bandar Udara (KKB), Pasal 18 ayat 1 , yang artinya mempunyai gangguan terbesar akibat operasi pesawat udara pada siang dan malam hari.

4. KESIMPULAN

1. Tingkat kebisingan di SDN 39 Sungai Raya, Kabupaten Kubu Raya telah melebihi ambang batas kebisingan untuk sekolah yang tertuang dalam Keputusan Menteri Negara Lingkungan Hidup Nomor KEP.48/MENLH/11/1996 yaitu sebesar 55 dBA. Tingkat kebisingan tertinggi di SDN 39 Sungai Raya yaitu sebesar 86,8 dBA.

2. Berdasarkan uji regresi menggunakan aplikasi SPSS didapatkan bahwa nilai pengaruh kebisingan terhadap waktu penyelesaian puzzle adalah sebesar $82,5 \%$. Hal ini membuktikan bahwa tingkat kebisingan mempengaruhi konsentrasi siswa dalam menyelesaikan susunan puzzle dengan benar.

3. Perlu adanya upaya dari pihak sekolah untuk meminimalisir kebisingan dari aktivitas penerbangan Bandara Internasional Supadio Pontianak yaitu dengan menambah jalur hijau, membuat kombinasi antara pagar beton (artificial barrier) dan pagar tanaman (natural barrier) serta menambahkan papan insulasi. Selain itu, perlu adanya pertimbangan untuk pemindahan lokasi sekolah ke tempat yang lebih kondusif yang jauh dari bandara atau minimal berada di bawah kawasan permukaan kerucut.

\section{UCAPAN TERIMAKASIH}

Terima kasih kepada Bapak Dr.rer.nat. Ir. R.M. Rustamaji, MT selaku Dekan Fakultas Teknik Universitas Tanjungpura, Bapak Dr. Ing. Slamet Widodo, MT selaku Kepala Jurusan Teknik Sipil Fakultas Teknik Universitas Tanjungpura, Ibu Dian Rahayu Jati, ST, M.Si selaku pembimbing utama, Ibu Laili Fitria, ST, MT selaku pembimbing pendamping atas waktu, nasehat, dan bimbingan yang diberikan selama penyusunan dan penyelesaian laporan, Ibu Drs. Dwi Astuti selaku Kepala SDN 39 Sungai Raya yang telah mengijinkan untuk dapat melakukan penelitian di sekolah tersebut, Kepala PT. Angkasa Pura II (PERSERO) Bandara Internasional Supadio Pontianak yang telah mengijinkan dan memberikan data yang diperlukan untuk menunjang penelitian ini.

\section{DAFTAR PUSTAKA}

Berglund, B. dan Lindvall, T. 1995. Community Noise. Archives of The Center for Sensory Research. Stockholm University and Karolinska Intitutet, Stockholm

Departemen Pekerjaan Umum. 2005. Mitigasi Dampak Kebisingan Akibat Lalu Lintas Jalan. Jakarta. Departemen Pekerjaan Umum

Karliani, A. 2014. Karakteristik Papan Insulasi dari Bambu dengan Variasi Jenis Core. Bogor. Institut Pertanian Bogor

Keputusan Menteri Lingkungan Hidup No. 48, 1996. Baku Tingkat Kebisingan, Menteri Lingkungan Hidup. Indonesia

Roscoe. 1975. dikutip oleh Uma Sekaran. 2006. Metode Penelitian Bisnis. Jakarta. Salemba Empat

Setyorini, R. P. 2015. Reduksi Kebisingan Akibat Lalu Lintas Menggunakan Pagar dan Dinding dari Material Lokal. Bogor. Institut Pertanian Bogor 